\title{
COMMENTARY
}

\section{Overcoming Past Perceptions and Profession-Wide Identity Crisis to Reflect Pharmacy's Future}

Jamie L. Wagner, PharmD, ${ }^{\mathrm{a}}$ Jaclyn Boyle, PharmD, MS, MBA, ${ }^{\mathrm{b}}$ Cynthia J. Boyle, PharmD, ${ }^{\mathrm{c}}$ David Choi, PharmD, ${ }^{\mathrm{d}}$ Jordan M. Ballou, PharmD, ${ }^{\mathrm{a}}$ Nimish Patel, PharmD, PhD, ${ }^{\mathrm{e}}$ Adam M. Persky, PhD, ${ }^{\mathrm{f}, \mathrm{g}}$ Daniel R. Malcom, PharmD ${ }^{\mathrm{g}, \mathrm{h}}$

${ }^{a}$ University of Mississippi, School of Pharmacy, Jackson, Mississippi

${ }^{\mathrm{b}}$ Northeast Ohio Medical University, Rootstown, Ohio

${ }^{\mathrm{c}}$ University of Maryland, School of Pharmacy, Baltimore, Maryland

${ }^{\mathrm{d}}$ University of Chicago Medicine, Department of Pharmacy, Chicago, Illinois

${ }^{\mathrm{e}}$ University of California San Diego, Skaggs School of Pharmacy and Pharmaceutical Sciences, San Diego, California

${ }^{\mathrm{f}}$ University of North Carolina, Eshelman School of Pharmacy, Chapel Hill, North Carolina

${ }^{g}$ Associate Editor, American Journal of Pharmaceutical Education, Arlington, Virginia

${ }^{\mathrm{h}}$ Sullivan University, College of Pharmacy and Health Sciences, Louisville, Kentucky

Corresponding Author: Jamie L. Wagner, University of Mississippi, School of Pharmacy, 2500 N State St., Jackson, MS 39216. Tel: 601-815-1933. Email: jlwagner@olemiss.edu

Submitted August 2, 2021; accepted October 4, 2021; ePublished October 2021

The profession of pharmacy has come to encompass a myriad of identities including apothecary, dispenser, merchandiser, expert advisor, and health care provider. While these have changed over time, the responsibilities and scope of practice have not evolved to keep up with the goals of the profession and level of education of practicing pharmacists in the United States. By assuming both the product-centric and patient-centric responsibilities for the aforementioned names, our true professional identity is unclear, which can be linked to the development and preservation of impostor phenomenon among the profession. For pharmacy to truly move forward, we need a unified definition for the profession by either letting go of past identities or separating these identities from each other through altering our standards within professional degree programs and practice models. Without substantial changes to the way we approach this challenge as a profession, the problems described will only persist and deepen.

Keywords: student pharmacists, pharmacists, impostor phenomenon, professional identity

\section{INTRODUCTION}

"What do you see when you look in the mirror?" The question is a rather simple one; however, for pharmacists, the answer is likely complicated and inconsistent across individuals and practice settings. Elaborate metaphors aside, the issue of how we respond to this simple inquiry related to our professional "reflections" is one of the core existential crises facing the pharmacy profession and, by extension, pharmacy education.

Many in the pharmacy profession who look in the proverbial mirror may see themselves reflected back wearing their white coats, proud of the service to others and commitment to excellence that the white coat represents. This identity development may begin with the symbolic White Coat Ceremony as students are prompted to consider their evolution towards identifying as a student pharmacist. As novice student pharmacists insert each arm into their new white coat and straighten the lapels to embrace the responsibilities of becoming a pharmacist for the first time, they may actually find themselves asking: "What does it really mean to be a pharmacist?" And yet, others who wear the white coat (or perhaps even those most proud of wearing it) may discover they now struggle with how others view them in their white coats.

The concept of impostor phenomenon (IP) may begin the moment that a student becomes a student pharmacist by donning their white coat. IP is defined as the internal experience of intellectual "phoniness" which is often experienced by high achieving individuals, who by definition are "focused on attaining success but never being satisfied irrespective of how much is achieved." ",2 These individuals, including pharmacists, may have fraudulent feelings when evaluating their current or future roles and responsibilities, while simultaneously never feeling satisfied. Literature has pointed to student pharmacists, pharmacy residents, and pharmacists experiencing IP feelings at various stages of their career. ${ }^{3-5}$ Although there is a large focus on understanding and overcoming IP, it must first be acknowledged that the emergence and presence 
of IP as a challenge in the profession cannot be extricated from the existential identity crisis facing pharmacy as a whole. Simply put, IP itself could be viewed as a symptom of the larger challenge encompassing all of pharmacy - "Who are we, and what is our role on the team and in the health care system?" This can be due, in part, to rapid advancements in science and technology, increased workforce pressures, and inherent public expectations that make defining the pharmacist's contribution to health care somewhat complicated. ${ }^{6}$

One way the pharmacy education system has tried to alleviate this professional identity crisis is through the requirement of interprofessional education (IPE) activities within pharmacy curricula. IPE activities are intended to help health care professional students understand their different roles, values, and perspectives they each bring to the table and to combine those assets into an effective, collaborative team. ${ }^{7}$ Unfortunately, despite these efforts, not only do pharmacy students still often fail to understand their role within the health care team, ${ }^{8,9}$ they are also not viewed as favorably as other professions. ${ }^{10}$ Initial feelings of inadequacy give way to professional identity formation over many years, as competence and confidence develop. The lack of clear roles and responsibilities for our profession has large impacts for trainees, practitioners, and the future of pharmacy. ${ }^{11,12}$ This ambiguity intensifies the IP that trainees and even practicing pharmacists may experience because they are unable to clearly articulate their role as part of the health care team. ${ }^{9}$ Though there is a sizable focus on recognizing certain aspects of individual IP and how to overcome it, this projects onto the identity crisis the profession is experiencing as a whole. If current pharmacists and the academy are unable to articulate the roles and responsibilities of a pharmacist under a unified definition, how can student pharmacists be expected to answer that call?

\section{DISCUSSION}

The image of pharmacy, as reflected by an individual pharmacist, is also complicated by the history and evolution of the profession over time. As pharmacy education has evolved from primarily product-centric responsibilities (BSPharm) to patient-centric responsibilities (PharmD), ${ }^{13}$ pharmacists should be prepared to assume new and emerging roles that may place them in uncharted waters. This initial move from the BSPharm to the PharmD in 2000 could have initiated the feelings of IP for the profession, as preceptors and educators with BSPharm degrees were forced to educate and train student pharmacists on a new identity that they themselves had yet to form. Or worse, and perhaps more likely in some cases, changes in the profession may have been unwelcome to some already in practice, particularly when those changes did not match up with corresponding changes to payment models. Regardless of the effect of the transition to the PharmD has had internally to the profession, the impact that pharmacists have on direct patient care outcomes is clear and convincing. Outcomes of pharmacist-led medication management continue to demonstrate positive impact for patients and the health care system; however, we have yet to truly define our role in the new value-based health care model. This and many other issues bring about the purpose of this article: to call to light the IP that the profession experiences, undoubtedly due to a lack of clear distinction of the role of a pharmacist in the $21^{\text {st }}$ century, and how we need to move past traditional perceptions to truly advance our profession forward.

\section{Evolution of the Roles and Responsibilities of Pharmacists}

Kellar and colleagues frame the five prominent pharmacist identity discourses as apothecary, dispenser, merchandiser, expert advisor, and health care provider over the past 100 years. ${ }^{11}$ But, the traditional, and most widely recognized, role of a pharmacist has been related to dispensing medications. ${ }^{13}$ Considering the highly regulated nature of the profession of pharmacy, these traditional responsibilities have included following rules and statutes, complying with controlled substance and other medication-related laws, and conducting transactional activities. Instead of focusing on outcomes, traditional responsibilities often force the pharmacist into a passive and compliant mindset. In 1985, the American Society of Hospital Pharmacists proclaimed that the profession would now be a clinical profession. ${ }^{14}$ While the American College of Clinical Pharmacy answered that call with their definition of "the area of pharmacy concerned with the science and practice of rational medication use", ${ }^{15}$ other pharmacy organizations did not publicly endorse this definition, leading us to still ask "what does it mean to be a "clinical pharmacist?"

In some respects, pharmacy programs are teaching all five roles, in addition to new opportunities which require enhanced skills and expertise, thus retaining the product-centric focus of more traditional pharmacist roles, as well as expanding to the patient-centric pharmacist roles seen today. ${ }^{16}$ Clinical pharmacists are supposed to be responsible and accountable for the safe and effective use of medications and optimizing clinical outcomes. However, this responsibility is not just relegated to pharmacists, as interprofessional teams may blur the lines of responsibilities in an effort to truly care for a patient. ${ }^{12}$ Despite the blurred reflection we may see, our profession should still be able to define our unique role in optimizing patient care. 
This baseline summarization of a pharmacist's role does not account for the modernization, changes, and evolution of professional training and the pharmacy job market in the past several decades that has led to the amalgamation of present-day pharmacy practice. It is imperative to acknowledge these significant developments in education, training, and responsibilities and their combined impact on pharmacists' identity within health care and as health care providers, or risk student pharmacists graduating without an appreciation for or understanding of their role. ${ }^{12}$

Many institutions recognized the need for post-graduate training by providing a facilitated learning environment to train future clinical pharmacists. There has since been significant growth in pharmacy services in various specialties, with several studies illustrating the increasing responsibilities pharmacists undertake in different patient care settings and their value as part of the interprofessional team. ${ }^{17-21}$ With the increase in post-graduate training opportunities, increased certification offerings, and job descriptions which require or prefer post-graduate education, pharmacists who lack this experience may have amplified impostor feelings when considering career changes. Further, fraudulent feelings may emerge when failing to secure post-graduate training or pursuing job opportunities when one may not fulfill all the stated job experience requirements.

Furthermore, with the sustained expansion of clinical activities across practice settings, pharmacists have continued to add more responsibilities without adjusting the language and definition of the profession to account for these modifications. For example, with the Centers for Medicare \& Medicaid Services Partnership for Patients program to decrease readmission rates, pharmacy departments around the country expanded to assist in transitions of care programs. ${ }^{22}$ However, a lack of staffing and financial resources to support these expanded services proved to be the most significant barriers in this effort. To account for the demand in additional staffing without added resources, pharmacy departments increased the scope of responsibilities and the profession exemplified its "diversification by edict" mentality, further impairing the lack of a unified identity for all pharmacists. For example, pharmacists have expanded into decentralized roles to support patient care performing clinical aspects such as antimicrobial stewardship, medication reconciliation, therapeutic drug monitoring. However, the profession's major source of funding/revenue is generated from the dispensing of medications. These pharmacists have now been tasked to take on more clinical work while still being expected to participate in the core role of dispensing medications at the same level they always have.

\section{Addressing the Pharmacy Identity Crisis}

To push the profession forward, we need to be mindful of several critical mistakes to avoid, as doing so could end up forcing the profession backwards. Kotter and colleagues developed an eight-step model useful for implementing organizational change; however, these steps can also be applied to the pharmacy profession (Table 1). ${ }^{23}$ The type of change suggested in this model will take time, though change pursued and implemented at too rapid a pace can have its own consequences. Both the academic and practice settings leave little room for error or failure, leaving many pursuing perfection despite its impossibility. Pharmacists may also feel the need to consistently validate their competence and justify their value. This maladaptive perfectionism leaves pharmacists being driven by fear of failure and an overwhelming need to hide their lack of perfectionism. ${ }^{24}$ The question arises, as pharmacy struggles with its identity, does this lead to the constant need to show value and self-worth? We need to examine this mindset closely and offer proactive methods for student pharmacists to prepare for not only the feelings of IP, but also coping with mistakes, insecurities, and self-doubt. ${ }^{25}$ Furthermore, this desire for perfectionism can also be driven by the need to meet expectations of the public and other professionals; however, do we even know what these expectations are?

\section{CONCLUSION}

We, as pharmacists, have struggled to recognize our proverbial reflections clearly in the mirror because we have no clear definition of what it truly means to be a pharmacist. In the absence of a unified definition, ${ }^{12}$ many pharmacists may attempt to live up to all the names and roles by trying to be all things to all people. This creates both an unreasonable and unsustainable expectation on the individual to live up to the unmet (and possibly unknown) expectations of the various constituencies in our lives and practice settings, thereby exacerbating the feelings of IP and overachievement. It is time to accelerate our practice transformation. ${ }^{26}$ Our profession needs to:

- Define and clearly articulate our role as the "medication expert" to other health care providers, the public, and ourselves.

- Push forward with achievable standards for the entire pharmacy profession in a way that demonstrates our effort and engagement to optimizing patient care. ${ }^{27}$

- Consider a tiered system within pharmacy education, as demonstrated within nursing education or pharmacy practice in the United Kingdom, thereby giving students the flexibility to determine which identity suits them best based on established definitions for the profession (Table 2). 
Perhaps it is time that we look in the mirror and truly ask ourselves - "Who do we see? Who do we truly want to be?"

\section{REFERENCES}

1. Clance PR, Imes SA. The imposter phenomenon in high achieving women: dynamics and therapeutic intervention. Psychotherapy: Theory, Research \& Practice. 1978;15(3):241-247.

2. Guidry CM, Medina MS, Bennett KK, Schwier NC. The other side of "challenging learners": strategies for teaching and precepting the overachiever and high performer. Am J Health-Syst Pharm. 2021;zxab348.

3. Sullivan JB, Ryba NL. Prevalence of impostor phenomenon and assessment of well-being in pharmacy residents. Am J Health Syst Pharm. 2020;77(9):690-696.

4. Boyle J, Malcom DR, Barker A, Gill R, Lloyd M, Bonenfant S. Assessment of impostor phenomenon in student pharmacists and faculty at two doctor of pharmacy programs. Am J Pharm Educ. 2021;85(5):Article 8474.

5. Henning K, Ey S, Shaw D. Perfectionism, the impostor phenomenon and psychological adjustment in medical, dental, nursing and pharmacy students. Med Ed. 1998;32:456-464.

6. John C. "The changing role of the pharmacist in the $21^{\text {st }}$ century." The Pharmaceutical Journal. 2018;300(7909). Last updated February 12, 2021. Accessed September 17, 2021. https://pharmaceuticaljournal.com/article/opinion/the-changing-role-of-the-pharmacist-in-the-21st-century

7. Jung H, Park KH, Min YH, Ji E. The effectiveness of interprofessional education programs for medical, nursing, and pharmacy students. Korean J Med Educ. 2020;32(2):131-142.

8. Curley LE, Jensen M, McNabb C, et al. Pharmacy students' perspectives on interprofessional learning in a simulated patient care ward environment. Am J Pharm Ed. 2019;83(6):6848.

9. Noble C, O'Brien M, Coombes I, Shaw PN, Nissen L, Clavarino A. Becoming a pharmacist: students' perceptions of their curricular experience and professional identity formation. Curr Pharm Teach Learn. 2014;6(3):327-339.

10. Thurston MM, Chesson MM, Harris EC, Ryan GJ. Professional stereotypes of interprofessional education naïve pharmacy and nursing students. Am J Pharm Educ. 2017;81(5):Article 84.

11. Kellar J, Paradis E, van der Vleuten CPM, oude Egbrink MGA, Austin Z. A historical discourse analysis of pharmacist identity in pharmacy education. Am J Pharm Educ. 2020;84(9):Article 7864.

12. Moore GD, Bradley-Baker LR, Gandhi N, et al. Pharmacists are not mid-level providers. Am J Pharm Educ. 2021; epub ahead of print:8566.

13. Carter B. Evolution of clinical pharmacy in the US and future directions for patient care. Drugs Aging. 2016;33(3):167-177.

14. American Society of Hospital Pharmacists. Directions for clinical practice in pharmacy. proceedings of an invitational conference conducted by the ASHP Research and Education Foundation and the American Society of Hospital Pharmacists. Am J Hosp Pharm. 1985;42(6):1287-1292.

15. American College of Clinical Pharmacy. The definition of clinical pharmacy. Pharmacotherapy. 2008;28(6):816817.

16. Boyle CJ. We are educating pharmacists, not "PharmDs". Am J Pharm Educ. 2020;84(9):Article 7829.

17. Thomas MC, Acquisto NM, Shirk MB, Patanwala AE. A national survey of emergency pharmacy practice in the United States. Am J Health Syst Pharm. 2016;73(6):386-394.

18. MacLaren R, Devlin JW, Martin SJ, Dasta JF, Rudis MI, Bond CA. Critical care pharmacy services in United States hospitals. Ann Pharmacother. 2006;40(4):612-618.

19. Holle LM, Harris CS, Chan A, et al. Pharmacists' roles in oncology pharmacy services: results of a global survey. J Oncol Pharm Pract. 2017;23(3):185-194.

20. Staino C, Lewin JJ, Nesbit TW, Sullivan B, Ensor CR. Survey of transplant-related pharmacy services at large comprehensive transplant centers in the United States. Prog Transplant. 2013;23(1):23-27.

21. Bacci JL, Bigham KA, Dillon-Sumner L, et al. Community pharmacist patient care services: a systematic review of approaches used for implementation and evaluation. J Am Coll Clin Pharm. 2019;2:423-432.

22. American Society of Health-System Pharmacists, American Pharmacists Association. ASHP-APhA medication management in care transitions best practices. 2013. https://www.ashp.org/Pharmacy-Practice/ResourceCenters/Transitions-of-Care?loginreturnUrl=SSOCheckOnly. Accessed March 19, 2021.

23. Kotter JP. Leading change: why transformation efforts fail. Harvard Business Rev. May-June 1995. https://hbr.org/1995/05/leading-change-why-transformation-efforts-fail-2. Accessed March 19, 2021.

24. Thomas M, Bigatti S. Perfectionism, imposter phenomenon, and mental health in medicine: a literature review. Int J Med Educ. 2020;11:201-213. 
25. LaDonna KA, Ginsburg S, Watling C. "Rising to the level of your incompetence": what physicians' selfassessment of their performance reveals about imposter syndrome in medicine. Acad Med. 2018;93(5):763-768.

26. Chase, PA, Allen DD, Boyle CJ, DiPiro JT Scott SA, Maine LL. Advancing Our Pharmacy ReformationAccelerating Education and Practice Transformation: Report of the 2019-2020 Argus Commission. Am J Pharm Educ. 2020;84(10):ajpe8205.

27. Ocampo ACG, Wang L, Kiazad K, Restubog SLD, Ashkanasy NM. The relentless pursuit of perfectionism: a review of perfectionism in the workplace and an agenda for future research. J Organ Behav. 2020;41:144-168. 
Table 1. Application of Kotter et al.'s 8-Steps for Organizational Change to the Pharmacy Profession

1. Create a sense of urgency.

As hard as it is to go outside our comfort zone, we need to examine the reality of the place of the profession within patient care, identify and discuss current obstacles, anticipate future obstacles, and capitalize on opportunities for change.

2. Build sufficient support behind the requested change.

Currently, there are over 21 national pharmacy organizations with competing interests within the U.S. While many of these have advocated for the profession to change, we are still lacking one unified message from all organizations on the professional identity of pharmacists. Currently, the roles of pharmacists and pharmacy practice vary from state-to-state and from institution-to-institution. Additionally, when examining the professional identities of other healthcare providers, it's no wonder pharmacists are confused, as our definitions closely resemble other providers' definitions. ${ }^{*}$

3. Formulate a clear vision amongst all pharmacy organizations for where the profession should progress.

First, we need to know what we need to change to become. What is our official definition for the pharmacy profession? Without this answer, we will be unable to move forward. Therefore, we need to join together with a specific direction and tasks to achieve this direction.

4. Communicate this vision sufficiently to all who need to hear it.

Once we have a clear vision, we need to be able to communicate the vision thoroughly to all invested stakeholders, including the public. By standing behind the vision, the organizations need to model this for all their members. Without clear communication on multiple platforms for this new vision, pharmacists in all practice settings will be

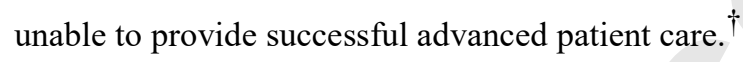

5. Remove current obstacles to make achieving our vision easier.

We need to remove current obstacles to making this change in the profession. Current guidance on advancing the profession to better optimize patient care leaves much ambiguity for ground forces to work with. Instead, clear steps on how to achieve this new vision, combined with the room to encourage nontraditional ideas, activities, and actions will aid in achieving our new professional identity.

6. Recognize any short-term wins. 
Each pharmacy organization that buys into this new vision for the profession should aid in creating ways for members to be innovative, and every small victory that gets our profession closer to our goal vision should be celebrated.

7. "It's not over until it's over."

We need to be in it for the long haul. Change this big does not happen overnight, nor will it happen within the lifecycle of organizational leadership. Therefore, we need to have systems in place to ensure that our vision continues to be reinvigorated and emphasized over time.

8. Institute succession planning to perpetuate the vision into the future.

Not only do we need to emphasize successes made toward making the vision a reality, but we also need to develop ways to continue this vision with subsequent generations of pharmacists. Specifically, we need to reinforce this vision within schools and colleges of pharmacy, as these are the student pharmacists who will eventually take up the mantle of our profession.

*Marks JW. Medical definition of Hippocratic Oath. MedicineNet. 2021.

https://www.medicinenet.com/hippocratic oath/definition.htm. Accessed March 19, 2021.

${ }^{\dagger}$ Dikun JA, Crumby AS, Shahpurwala Z, Hall J, Charrois TL, Rosenthal MM. J Am Pharm Assoc (2003). 2016;56(6):649-655. 
Nursing Profession*

Certified Nursing Assistant

Licensed Practical Nurse

Registered Nurse

Advanced Practice Registered Nurse
Responsibilities:

- Serve as primary point of contact between patient's family members and healthcare organization

- Assist with patient's activities of daily living

- Administer medication, take vital signs, complete charting requirements Requirements:

- High school diploma or GED

- Completion of state-approved CNA program

- Pass a state-approved exam

Responsibilities:

- Serve as primary communicator between the care team and the patient

- Communicate with the patient's family

- Monitor patient health

- Take vital signs, start IV's, change bandages Requirements:

- Successful completion of a Practical Nursing Program

- Pass the National Council Licensure Examination for Practical Nurse (NCLEX-PN)

Responsibilities:

- Administer medication

- Contribute to a patient's plan of care

- Collaborate with physicians

- Oversee CNAs and LPNs

Requirements:

- Earn either an Associate of Science in Nursing or a Bachelor of Science in Nursing degree

- Pass the NCLEX-RN exam

Responsibilities:

- Perform all duties of a RN

- Direct the plan of care

- Diagnose and treat illnesses

- $\quad$ Prescribe medication (with or without physician supervision)

- Advise on public health issues

Requirements:

- Currently hold a RN license

- Minimum 1 year work experience as a RN

- Earn a Master of Science in Nursing

- Pass the American Academy of Nurse Practitioners Certification Board exam

Pharmacy in the United Kingdom ${ }^{\dagger}$

Pharmacy Assistant / Medicines Counter Assistant

Pharmacy Technician
Responsibilities:

- Order, prepare, and dispense medications

- Answer patient questions

Requirements:

- 2-3 years of General Certificates of Secondary Education (Grades 9-11)

- Some relevant work experience

Responsibilities:

- Manage and prepare the supply of medications

- Give advice to patients and customers

- Supervise Pharmacy Assistants

- Refer patients to another healthcare professional

Requirements: 
Pharmacist

- 4 years of General Certificates of Secondary Education

- Complete a 2-year accredited pharmacy technician course

- Register with the General Pharmaceutical Council

Responsibilities:

- Use expert knowledge of medicines and health to make a positive difference in patient lives

- Help patients live healthier lifestyles

- Optimize medications

Requirements:

- Complete a 5-year program of academic and practice-based teaching (4 years resulting in a Master's in Pharmacy; 1 year in a paid work placement)

- Register with the General Pharmaceutical Council

\footnotetext{
*University of St. Augustine for Health Sciences. "Levels of Nursing Explained." Updated February 2021. Accessed September 17, 2021. https://www.usa.edu/blog/levels-of-nursing-explained/

†National Health Service. "Roles in pharmacy.” Accessed September 18, 2021. https://www.healthcareers.nhs.uk/exploreroles/pharmacy/roles-pharmacy
} 